INTERNATIONAL DESIGN CONFERENCE - DESIGN 2018

https://doi.org/10.21278/idc.2018.0349

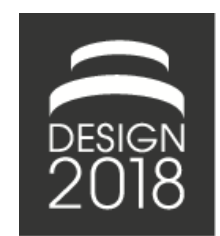

\title{
FRAMING NEW PRODUCT INNOVATIONS: HOW TO MAKE SENSE OF INTERNAL AND EXTERNAL INSIGHTS?
}

\author{
L. N. Laursen and L. M. Haase
}

\begin{abstract}
This study examines: How experts make sense of internal and external insights when they create new product innovations. It focuses on the experts' reasoning; and suggests a model for internal/external sense-making based on framing theory. The model is tested in three emblematic cases in respectively B\&O, Coloplast \& Vipp. The study reveals, that experts make sense by reapplying frames from previous internal products as well as adopt frames from external inspirational products. Hereby they both create coherency with the brand, but also update the product to match new emerging values and trends.
\end{abstract}

Keywords: design driven innovation, framing, innovation, design theory, design models

\section{Introduction}

New ground-breaking innovations are often found to combine different kinds of knowledge and insights in new unforeseen ways (Fleming, 2001; Rosenkopf and Nerkar, 2001). In many instances the ability to recombine knowledge and create innovative concepts, requires insights from both within and outside the firm (Grant, 1996; Chesbrough, 2003; Cassiman and Veugelers, 2006). Studies have shown that whereas many companies benefit by an internally developed knowledge base, this knowledge base alone is not sufficient to support new product innovation (Nelson and Winter, 1982; Anderson and Tushman, 1990). Valuable knowledge is to be found outside the company (Cohen and Levinthal, 1994) and accessing and integrating this knowledge into the innovation process is crucial for any company's innovative performance (Rosenkopf and Almeida, 2003).

The focus on combining and integrating both internal and external insights is also a key element in design and innovation process models (Ulrich and Eppinger, 2008; Buijs, 2012). For example in the 'Delft Innovation Model', Buijs (2012) suggests a set of analysis and interactions related to the inside of the company (e.g. core competences, strategic strengths and strategic planning) as well as a set of analysis related to the outside environment (e.g. market gap analyses, user analysis etc.). Similarly, the importance of combining internal and external insights is also accentuated in studies on design driven innovation (see e.g. Acklin, 2009; Dell'era and Verganti, 2009; Dell'Era and Verganti, 2010; Filippetti, 2011; Calabretta et al., 2015). In fact, the 'Design-Driven-Innovation Management Model' suggests interaction between the internal company and the external environment, both when it comes to: impulses, research, development, strategy, implementation and evolution (Acklin, 2009).

Both within the field of innovation management as well as within the field of design management considerable amounts of research have focused on how to manage the internal and external insights, ideas and actors (see e.g. Arora and Gambardella, 1990; Grant, 1996; Chesbrough, 2003; Karim and Mitchell, 2004; Cassiman and Veugelers, 2006; Phene et al., 2006; Bercovitz and Feldman, 2007; 
Sampson, 2007; Dell'era and Verganti, 2009). However, the way in which experts make sense of these internal and external insights, and on the basis of this create a product concept, still remains a black box.
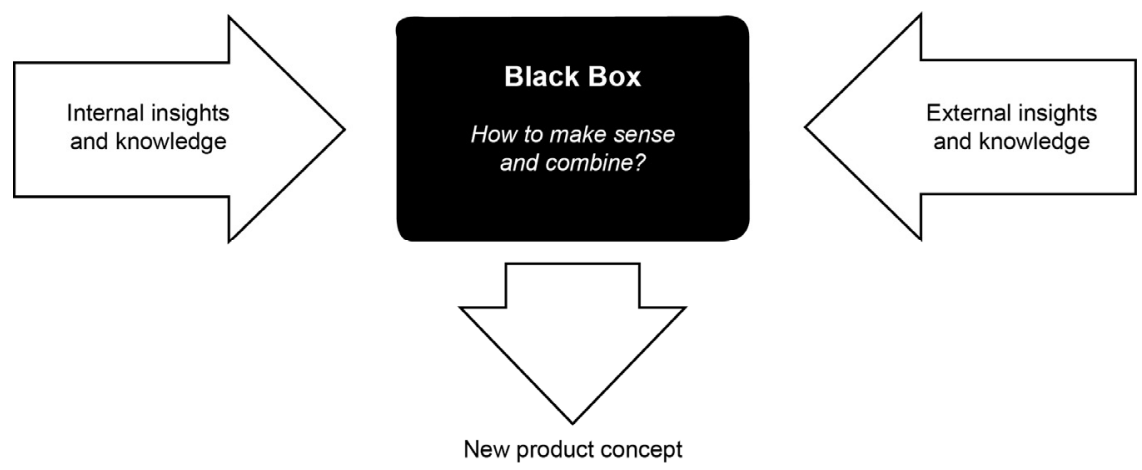

Figure 1. How to make sense and combine internal and external insight?

Differing from prior studies, the aim of this study is to explore how experts (designers and innovators) make sense of the internal and external insights and combine these insights into new product innovations. Instead of looking at how to manage this process or the actors in it, we propose it is more meaningful to shift focus from what can be seen on the outside, to look at how the experts reason. Hence, the research question of this study is: How do experts make sense of the internal and external insights in the innovation process and how do they reason to combine these insights into new product concepts?

In this study, we tend to the design literature, more specifically the theories on framing (Schön, 1983; Schön, 1995) in order to understand, how experts make sense of different insights and combine these into new product concepts. Since framing initiates an abductive reasoning process, it allows the designers to simultaneously create a way to understand the insights they have, as well as set direction for the solution (Dorst, 2011). Hence we propose the concept of framing may be valuable in clarifying core aspects of integrating internal and external insights into the innovation process.

Based on framing theory we develop an internal/external sense making model. In the empiric part of our study, we use the theoretical model to examine three in-depth case studies of how designers reason in respect to innovative products, at three firms: respectively B\&O, Coloplast and Vipp.

\section{Framing a way of making sense of the internal and external insights}

The task of combining different insights into a product concept, is opposed to traditional problem solving tasks, an open-ended, ill-defined and unique problem, which is also denoted a wicked problem in literature. Wicked problems have no definitive definition and due to this uniqueness it is not possible to solve them just by adopting previous solutions (Rittel and Webber, 1973; Buchanan, 1992). When faced the task of creating a new meaningful product concept, the designers or innovators need to make decisions about an unknown future having only incomplete, ambiguous and contradicting insights available (Valkenburg and Dorst, 1998; Dorst, 2011) Recent studies shows that in order to handle wicked problems designers reason through frames (Dorst, 2011). This means that the frames serves as a way to handle the ill-defined and open-endedness, which other problem solving methodologies fail to handle (Dorst, 2011). The process of framing allows the designers to simultaneously create a way to understand the insights they have (e.g. prioritizing, combining and making sense), as well as set direction for the solution (Dorst, 2011). Thus, framing may be defined as an approach, that deals with the situation of having various insights available, and then having to figure out ways of combining and these into a meaningful concept (Dorst, 2015).

A frame may be defined a proposal for 'HOW a solution' could work in order to achieve 'an aspired VALUE' (Dorst, 2011). In a wicked problem situation, we do not know upfront 'WHAT to design' or 'HOW the solution' is going to work. Framing allows the us to create an intuitively meaningful proposal and afterwards test whether this proposal holds true (see Figure 2). By proposing a frame, we get a way of understanding the problem as well as a new way of acting within this problem (Dorst, 2015). 
Accordingly, the creation of a frame allows the us to engage in a process of abductive reasoning; a process of sense making (Schön, 1983; Weick, 2001).

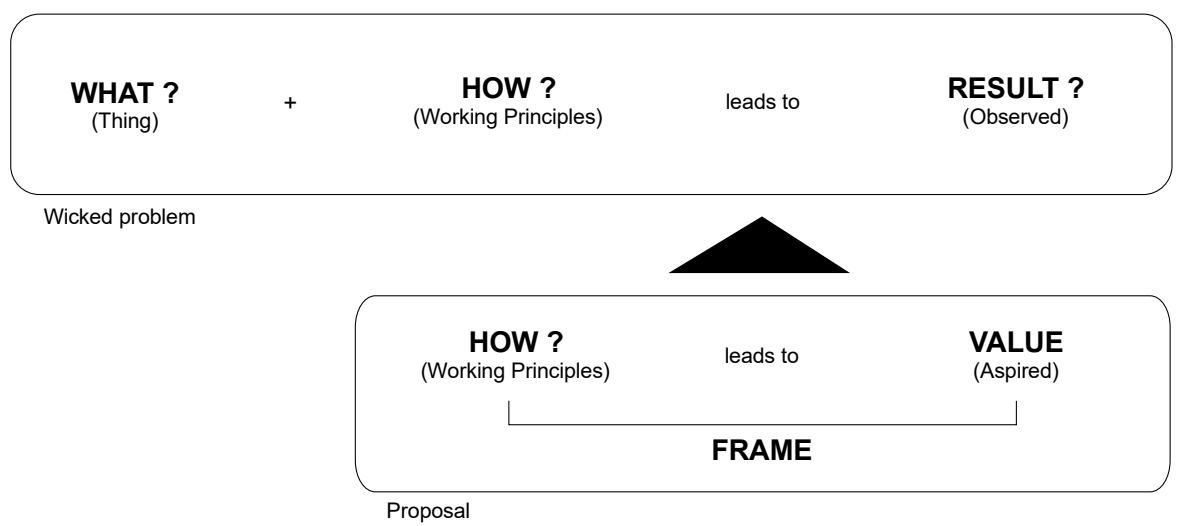

Figure 2. Tackling wicked problem through framing (buidling on Dorst, 2011, pp.

523-524)

A recent study of expert reasoning in the fuzzy front end of innovation further unfolds the structure of frames (Haase and Laursen, 2018). The study shows, that the framing process is initiated by 'an insight' that leads to an envisioned change. Thus, frames create a proposal of how to interlink; not only an aspired value and solution principles, but how these are built from insights in respect to different aspect of the product e.g. main user paradox, experience, expression, market, brand etc. (Haase and Laursen, 2018). Hence, frames connect 'an insight', 'an aspired value' and 'a working principle' (as illustrated in Figure 3). The essence of these frames is captured in or expressed as metaphors or storytelling.

\begin{tabular}{|c|c|c|c|c|}
\hline \multicolumn{5}{|c|}{$\begin{array}{c}\text { Frame } \\
\text { 'Expressed by metaphor' }\end{array}$} \\
\hline Insight & $\rightarrow$ & Aspiration & $\rightarrow$ & Working Principle \\
\hline
\end{tabular}

Figure 3. The frame as an interlink between insights, aspired value end working principles (based on Haase and Laursen, 2018)

\subsection{A model of 'how designers make sense of internal and external insights'}

Based on the insights from framing theory, we propose a model for how experts make sense of internal and external insights in the innovation process. The model suggests the reasoning of experts may be understood as frames that either captures the important and complex insights from within the company (internal insights) or from the context surrounding the company (external insights); and that these together reflects the sense-making behind the product (see Figure 4).

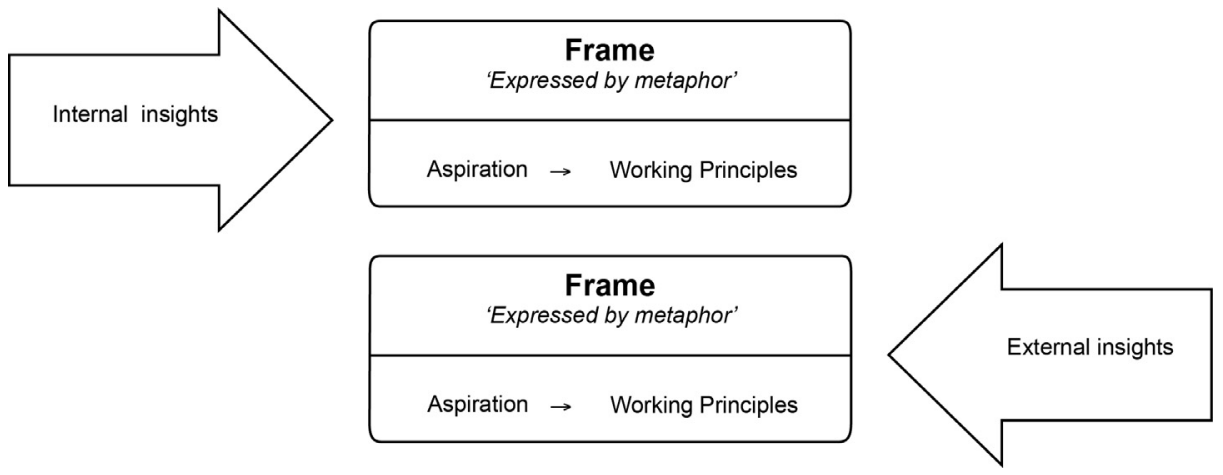

Figure 4. A model for understanding the sense-making behind products 
In the remaining part of the paper, we refer to this model as: 'The internal/external sense making model' and in the following it will be use for examining experts reasoning in respect to three emblematic cases.

\section{Research design}

Since the understanding of how experts make sense of the internal and external insights and combine these into product concepts, is well understood in current literature; an examination of the question indepth in its real-life context is appropriate to enhance our understanding and further knowledge building (Eisenhardt and Graebner, 2007). Albeit qualitative case-studies, may provide messy data, they are often the most suitable way to reach sufficiently deep insight, when the questions are of 'how' and 'why' variety (Yin, 2009) as in this study.

The cases are retrospectively selected, based on a purposeful information-oriented sampling. Information-oriented selection may be regarded a purposeful sampling strategy, in which information rich case that enlightens the matter of interest is selected. Potential cases were evaluated based on their probability to offer interesting insights and accessibility, rather than for its ability to represent a broader population (Stake, 1995) "To maximize the utility of information from small samples and single cases. Cases are selected on the basis of expectations about their information content" (Flyvbjerg, 2006, p 15). Accordingly, the research includes case studies at three Danish firms; respectively $\mathrm{B} \& \mathrm{O}$, Coloplast and Vipp. In connection to another study, we identified these three firms to be faced with a particular interesting challenge, when they create new products. All three firms have a long design history (B\&O was established in 1952, Vipp in 1939 and Coloplast in 1954), hence a well-established design DNA (Haase and Laursen, 2018). This made us curious of; how these firms reason to unify the internal history of their product DNA with the changed external context. Moreover all three firms offer products at a premium price-range in their market by using design as their main differentiating parameter, thus they may be regarded as firms who place sense making in centre of the product innovation process.

In each of the firms a particular information-rich 'product innovation case' were selected, through an information-oriented selection. In order to be able to study 'the creation of new product meaning' the core parameter in the case selection were, the cases represent a radical leap, compared to the firms previous portfolio. In collaboration with the firm we looked for cases of product innovations already on the market. Despite the fact, that retrospective studies may present reliability-questions, the gain of selecting the cases in hindsight is, that it ensures relevant cases suitable to study the matter of interests. This is particular important, since reasoning is a complex and chaotic phenomenon to study and the boundaries around the phenomenon is fuzzy. As such the cases were based on their ability to enlighten the matter of focus, rather than for their ability to represent a broader population.

Data was collected through multiple sources, but the primary the data collection were in form of semistructured interviews. Compared to other data collection approaches such as surveys, observations etc., the interviews enables access to an earlier otherwise closed internal thought-process and reasoning. Thus, we used an open, semi-structured, non-directed interview form in order to learn and be surprised by the insights.

The informants were selected based on their depth and quality of insights (Eisenhardt and Graebner, 2007), hence their knowledge of the matter of interests. More specifically, we looked for people "that are uniquely able to be informative because they are expert in an area" (Weiss, 1995, p.17). The informants all worked as internal designers, either in the lead (as head designer or decision maker) or as part of the teams.

The respondents were teams of expert designers or innovators. The teams included 3-5 key members as well as some consulting members. In terms of expertise: we selected teams where most members had 10 years plus experience in the industry. All key members were interviewed one or more times. The semi-structured interview guide evolved around the selected cases of products already on the current market. It was structured from the informants' perspective starting off with an introduction of themselves, the firm and the product case, moving into the raison d'être of the innovation and chronologically, into the reasoning and choices made in the development, covering the how internal and external insights shaped the reasoning. Having the intimate nature of reasoning in mind all interviews 
were conducted face-to-face in order to establish a connection, enhance confidence and data richness (Eisenhardt and Graebner, 2007).

The interviews were all audio recorded and the points of interests were noted down. Furthermore, important parts of the interviews were transcribed. The data was analysed according to the developed model of internal/external sense-making. First dividing the reasoning into insights, aspired value, frames and solution principles. In the second step the findings were categories according to internal insights (e.g. brand, core capabilities etc.) or external insights (e.g. changes in market, trends etc.) and in the third part of the analysis characteristic patterns emerged from the categories.

\section{Case analysis}

In the following case analysis, the wording is deliberately kept true to the informants' original explanations, to give the reader an insight in the informants' rationale, hence how they make sense of the internal and external insights. This means the case analysis includes the informants' storylines, which may display a somewhat commercial, branded or subjective view of the products. As we are interested in studying the experts' sense making and rationale in respect to the internal and external insights (not whether it is objectively a good product or not) staying true to their reasoning was priority.

\subsection{Bang \& Olufsen: Beoplay A9}

Beoplay A9 is one of the first products launched from B\&O's sub-brand, B\&O Play. A9 is a music system, designed, as a piece of furniture, that is crafted with legs of wood and cover of fabric.

The initial external insight the A9 is built on is, that in opposition to previously, young people are not introduced to the $\mathrm{B} \& \mathrm{O}$ brand through their parents. Past $\mathrm{B} \& \mathrm{O}$ products, do not look anything like the kind of products young people buy today, they represent these great black sculptures. Therefore, the overall aspiration with the A9 was to introduce young people to the $\mathrm{B} \& \mathrm{O}$ quality and experience, through working principles as mirroring other products, young people use e.g. mac products or modern furniture, like the Eames chair. The sense making was expressed it is a designer chair and not a pretentious sculpture'.

A second external insight that was integrated into the A9 was that; young people live less static lives than previously. They move from apartment to apartment, and hence the great installation and integration into the house that most $\mathrm{B} \& \mathrm{O}$ products require, are less attractive to the young target group. Therefore, the aspired value became create a product that was easily moved and replaced without any stationary installations, which Bang \& Olufsen earlier products were famous for. The framing was called: 'placeability' or 'go where the party people are'.

A third external insight that the A9 is built on is that the shape of many objects in music are 'round' e.g. the $\mathrm{CD}$, the volume button, the tuba etc. The aspired value was to express this timeless shape of music in the A9. The frame was called: ' $B \& O$ round' or 'The large tuba'.

The last external insight that was integrated into the A9 was: that access to unlimited music services may make it difficult to select music and slow down the process of turning on music. The aspiration was to create a product that would start playing easily and instantly- making it easy to master, even for the guests without pre-instructions. The frame was called the 'the hand on the product', so the working principle became instead of a remote you can control the music by stroking it.

The internal insights that was integrated into the A9 was related to B\&O's long tradition for craftsmanship and detailing in respect to hi-fi products. The aspiration was to transfer this into the current products, in the product development the team called this frame the 'B\&O Craftsmanship'. It influenced a lot of the detailing of the product - including working principles as the beautiful pattern on the back of the product, that would allow for base-sound to come out, in order to hinder movement of the front cover. 

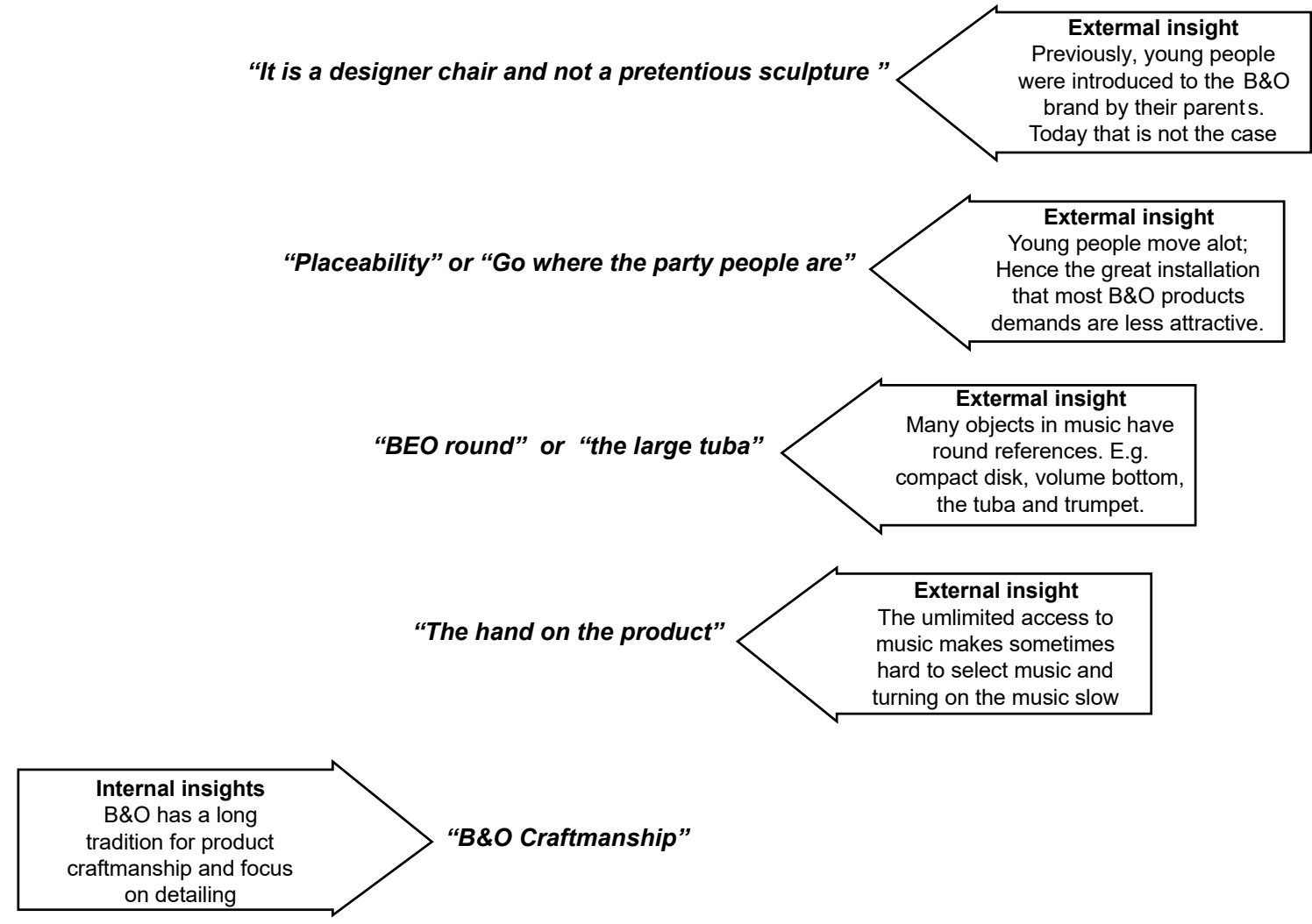

Figure 5. The product meaning frame created for Beoplay A9

\subsection{Coloplast: SenSura Mio}

Sensura Mio is an ostomy bag developed by Coloplast. It is based on the external insight that the emotional challenges of getting an ostomy is huge, and for the patients it often feels like they are losing their dignity. Present ostomy bags have prosthesis expression that easily makes the patients feel stigmatizes as handicapped or sick. Accordingly, the aspired value was to create an ostomy bag, which would be just like: 'a piece of clothing'.

Another external insight that is integrated into SenSura Mio is that presently, all ostomy bags are made from cheap plastic material, that is uncomfortable to wear. The aspiration is to create a product that is comfortable to wear and that provides 'material dignity'.

A third external insight key to the Sensura Mio is that present ostomy bags imitates white 'skin colour', which makes it look strange or even 'wrong' on other skin colours. Further, this colour is visible under white clothing. Hence the aspired value was to create a product that would look perfect on every skin and never become visible under any clothing. The framing for this insight is: 'Become one with the shadow'.

Finally, Sensura Mio was built on all the internal insights and knowledge in Coloplast, in respect to hindering leakage and bad smells. The framing of this was called: 'Security first' and the aspiration was to induce the patients with the Coloplast feeling reliability and security; including a lot of working principles from previous products and on-going R\&D such as: 1) a 'gluedisk' that fits all body shapes and sizes that may be positioned and removed from the body without causing damage to the skin, 2) different layers of materials in the bag to prevent leakage of fluid and smell, while allowing for the possibility of looking into the bag if needed and 3) a new filter system for air-transmission that lowers the probability of ballooning. 


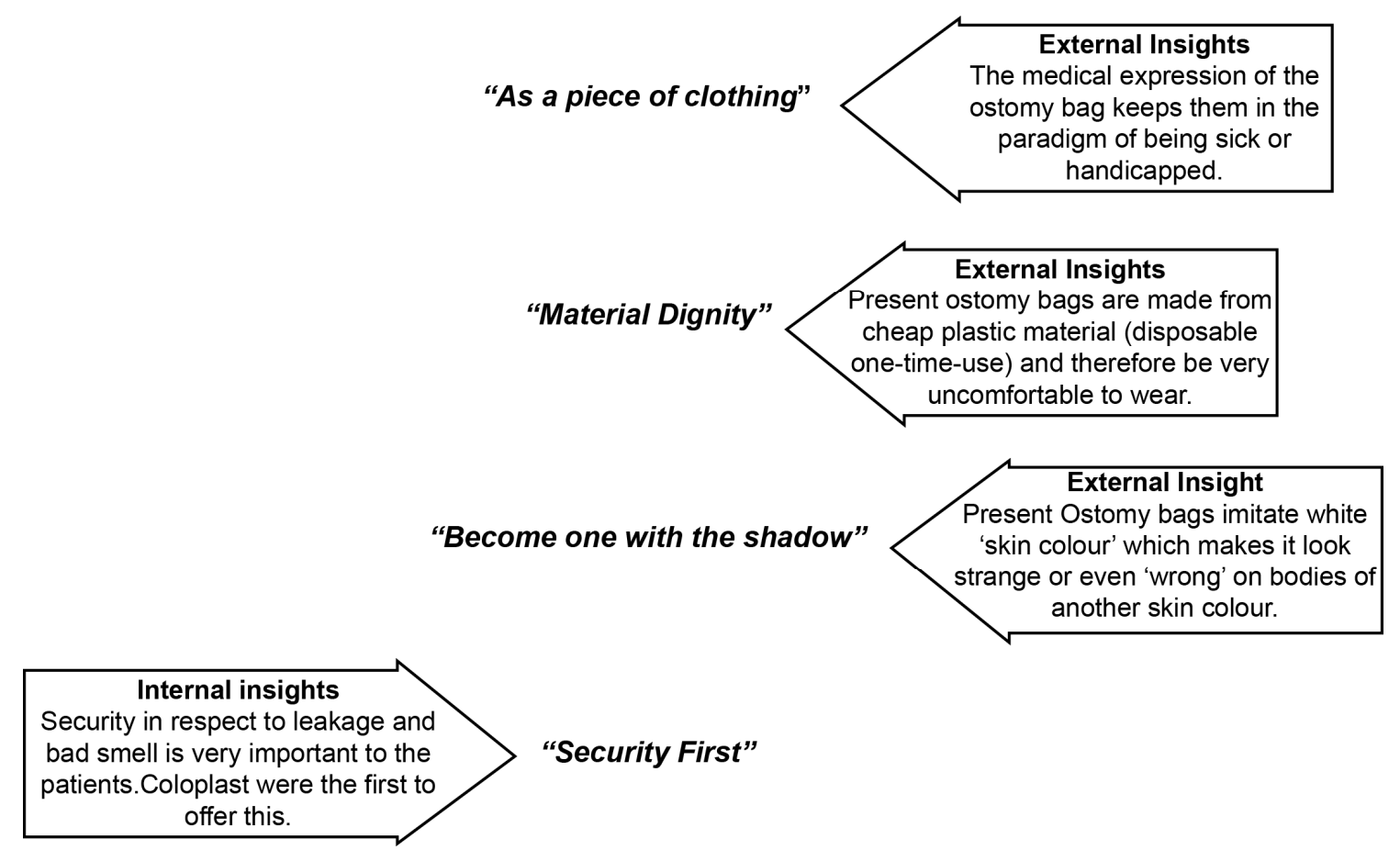

Figure 6. The product meaning frame created for Sensura Mio

\subsection{VIPP: Kitchen}

The Vipp kitchen is a high-end stainless steel kitchen, which builds on the design DNA of the Vipp pedal bin. The Pedal bin was designed back in 1939 and known for its durability and classic expression. Previously, The Vipp bin was sold as accessory to new kitchens in various kitchen retail stores, however Vipp was dissatisfied with this arrangement, mainly because the kitchens are fashion products with limited lifetime and Vipp bins are made to last for decades. To approach this internal insight Vipp decided to create 'a kitchen to go with the bin' in terms of a long-lasting, well-built kitchen, which costumers can keep for many years and even bring along, if they move.

Another internal insight that the Vipp kitchen is built on is that: the DNA of Vipp is to create everyday tools with improved interactions. The aspired value therefore is to create a kitchen, that is not only for show, but a tool that will be used by people, who love to use it. The frame is called: 'It is a tool' and one of the key working principles is that in all the 'places' where the user interacts with the product more attention is added to the details.

A final internal insight, that the Vipp kitchen is built on is that some of first Vipp pedal bins are still in use 40 years after they have been produced. The aspired value is to create a kitchen with the same durability and lifetime. The frame for this is called: 'demonstrating craftsmanship' and one of the key working principles is that all elements of kitchen can be repaired. There will be used no glue or popnettings.

The Vipp kitchens is also built on two external insights. The first external insight is that the market for online shopping of kitchens is starting to mature. Vipp wants to tap into this new sales channel and therefore the aspired value becomes to create a kitchen that is optimized for online sale. The frame is called: 'Ford T-type choices' which points to working principles such as minimising choices and variables so the kitchen can be planned very fast.

The second external insight that Vipp kitchen is based on, is that most costumers will be international due to the expected price of the kitchen, and therefore installation needs to be simple enough to be handled by local installers. Hence, the aspired value was very little interface with existing structures in the room, where the kitchen will be installed in order to minimize the challenges in the installation. The 
frame is called: 'free flowing boxes' and refers to working principles such as freestanding modules with adjustable legs and variable in length only.

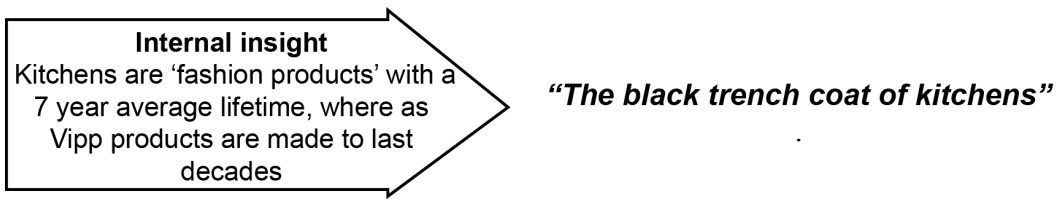

“Ford T-type choices"

External Insight

The market for online shopping of kitchens is starting to mature. VIPP wants to be globally present and tap into this new sales channel
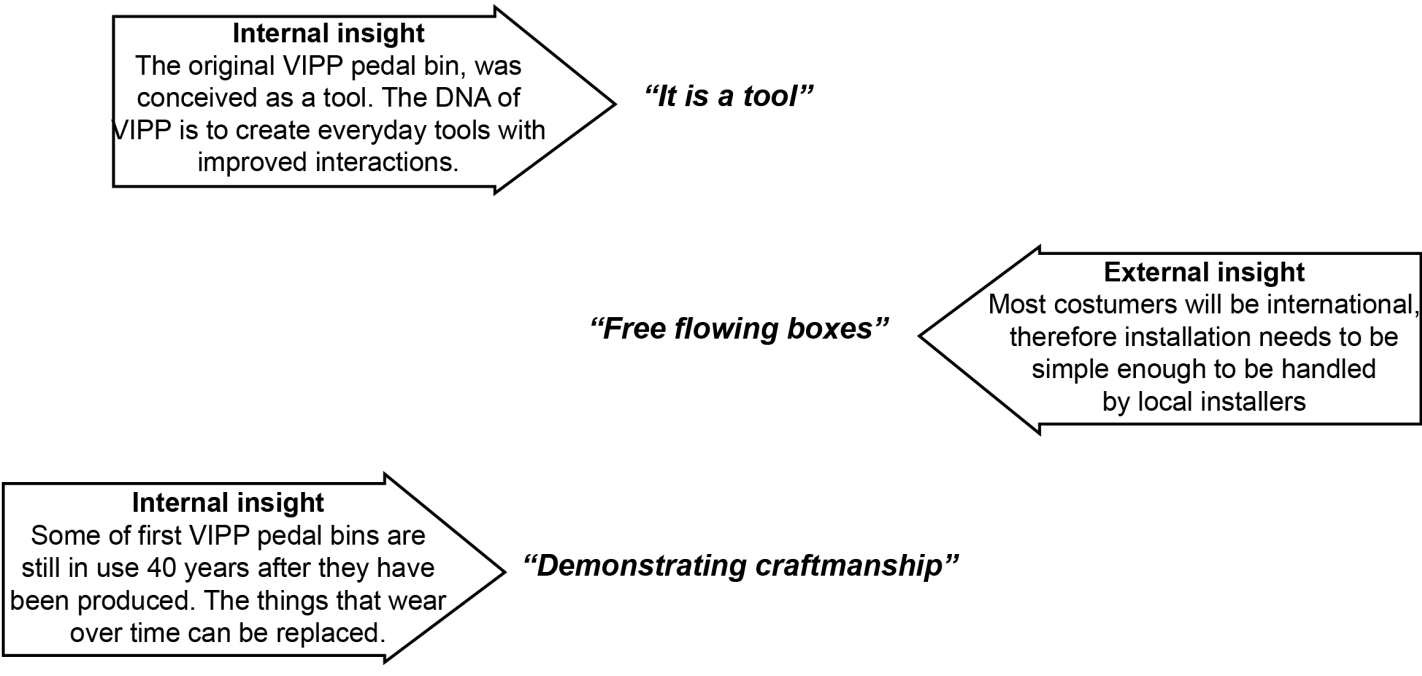

Figure 7. The product meaning frame created for Vipp Kitchen

\section{Cross-case analysis}

When comparing the three cases a number of interesting findings emerge.

Firstly, analyzing the cases according to the internal/external sense-making model reveals that the experts are very specific in their explanation of the product. All of them have a well-structured storyline. Furthermore, in the teams it is obvious that they are quite aligned in their understanding of the product, they have developed a common understanding of the internal and external insights which are essential in conceiving the product. Our reason for concluding this is, first of all, that the experts are very precise about what the product is and what it is not, why it has certain features and others have been deselected. Furthermore, all the experts or teams have created a number of metaphors, which frames the way they make sense of the internal and the external insights in respect to the product. During the interviews, the informants continuously refer to the metaphors. They emerge again and again during the interview, making it evident the experts already had their sense making in place and aligned when we interviewed them. Thus, we find that the experts make sense of the internal and external insights by framing them and that our internal/external sense making model represents a way for externals to understand the our internal/external sense making structure and communicate them.

A second interesting finding is that the way the designers make sense of the internal insights, is by searching for frames within previous products of the brand, that will by sensible to apply. Rather than using internal insights and knowledge in any given way, the designers actively reapply frames from previous products. This means that the framing in the previous products are used as stepping stones for transferring desired brand values or product characteristics into the new product. For instance, in the SenSura Mio case the frame called 'security first' is a frame that is key to Coloplast's product success, 
this frame is reapplied into the SenSura Mio. Likewise, in the Vipp kitchen case, the two frames: 'demonstrating craftsmanship' and 'it is a tool' were transferred from the pedal bin, which is still regarded as Vipp's most successful product. Thus, the new products draw upon pervious sense making from inside the companies and thereby ensure that there is consistency and reconcilability between the new and the old products. As the second finding we discover designers make sense of the internal insights, by reapplying pervious product frames.

A third and interesting finding, that emerge when looking across the cases, is that rather than just using external insights and knowledge on e.g. users' dilemmas, emerging technologies or changes in society etc., the experts seems to be looking for frames in other external inspirational products, as a way of making sense of the external insights. We find experts are looking for sense making within other products, that can be used as stepping stones for creating the new or renewed product frame, to be used in the specific product, they are designing. For instance, in the B\&O A9 case, the Eames-chair is used as key inspiration for the frame "it is a designer chair and not a pretentious sculpture". In the design of the A9 some of the features from the 'Eames chair' is even transferred directly - most strikingly the wooden legs. In the Sensura Mio case the sense making embedded into clothing is in many ways renewed and applied into the context of ostomy bags e.g. in the framing 'material dignity' which refers to a trend within the fashion industry, that the designer it transferring to the design of osteotomy bags.

Thus, we find experts make sense of external findings by directly searching for new frames that matches the changing values in society.

A final interesting finding that emerge, if we zoom out and look at the result, it is evident that all three products are balancing between; being new and innovative, and at the same time keeping in line with the brands, they are part of. They are doing this by adopting and combining both internal and external frames. On one hand, they are building on some of the frames from previous products within the brand that ensures that there is coherence and recognisability, between the new and the old products within the brands. On the other hand, they are building on way of making sense in other product categories by adopting frames from these or by identifying inspirational products as a way of making sense of the external insights. E.g. in the B\&O A9 case, the external frames "It is a designer chair and not a pretentious sculpture"; "place-ability" and "the large tuba" ensures much needed renewal of B\&O play product, in respect to other traditional $\mathrm{B} \& \mathrm{O}$ products; however, the internal frame: " $B \& O$ craftsmanship" ensures close connection between the new and the old products. Thereby, we find experts ensure both renewal as well as coherence, when combining frames both in respect to the internal and external insights.

\section{Discussion and implications}

Differing from prior studies, on how to manage internal and external insights in the development process, this paper aims to explore, how designers make sense of internal and external insights. Instead of looking at how projects are managed, organized and structured in relation to the intense interactions between internal and external actors, we studied experts reasoning, in order to deepen our understanding of how they make sense of the internal and external insights and how they combine these into remarkable new products.

Through the examination of the three product cases, we discovered that the internal/external sensemaking model is a valuable tool to unfold the sense making behind the products. The model provides insight into how this sense making behind the products is created, because it shows how the different insights both internal and external to the companies, are interlinked with aspired values and solution principles - in frames.

As such, this study contributes with an understanding of 'How experts make sense of the internal and external insights and how they reason to combine these insights into new product concept. The study shows that:

- Experts make sense of the internal and external insights by framing them

- Experts make sense of the internal insights by reapplying frames from the repetition of the firms' previous product designs.

- Experts make sense of the external insights by looking for frames in product outside their category or for inspirational products as a way of making sense of the external insights. 
- Experts reapply frames from previous products, to maintain consistency and coherency and to carry on the internal product DNA of the firm, but at the same time, they combine it with new frames based on inspiration from external products, to meet the emerging values and changes in the surrounding society.

We use these findings to update the internal/external sense making model (Figure 8). The model shows that creating a remarkable product concept within an existing brand is a matter of combining: 1) Internal frames, that are reapplied from previous products to create coherency with the previous products and leverage on the firms brand and product DNA, with 2) external frames from trending/aspirational products on the market, which captures and make sense of new emerging values or trends, and used these renewing frames to update the product and create novelty.

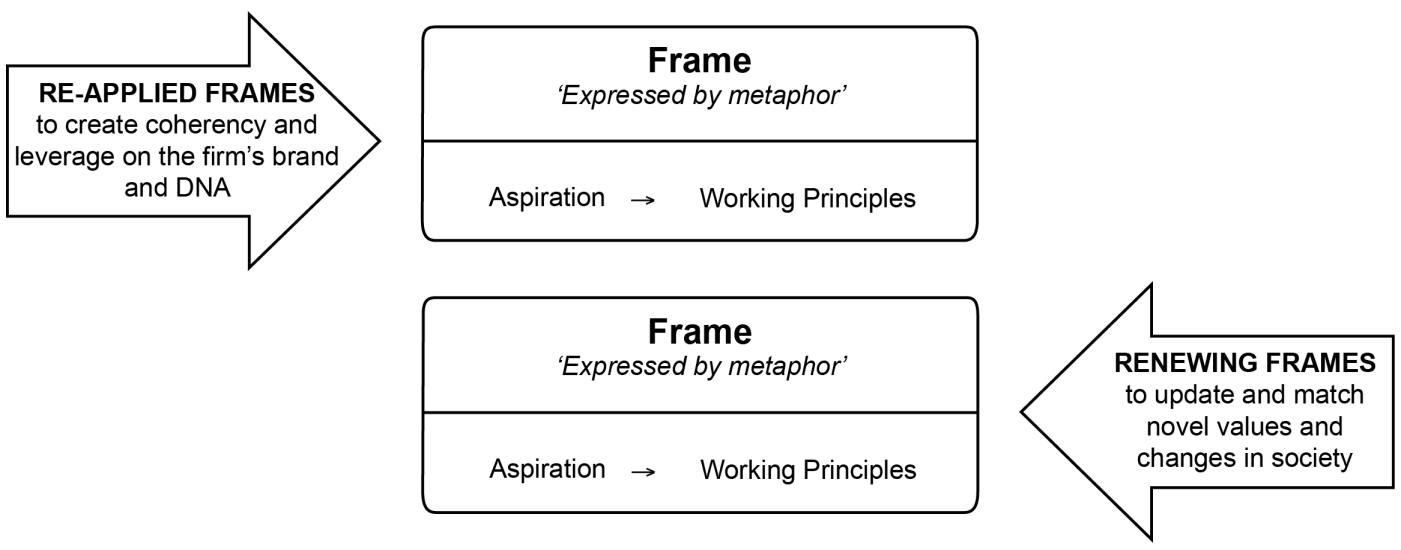

Figure 8. The internal/external sense-making model

This study contributes to present research on how to manage the internal and external insights in the innovation process. Differing from prior studies (e.g. Arora and Gambardella, 1990; Grant, 1996; Chesbrough, 2003; Karim and Mitchell, 2004; Cassiman and Veugelers, 2006; Phene et al., 2006; Bercovitz and Feldman, 2007; Sampson, 2007; Dell'era and Verganti, 2009) this project focus on the reasoning of experts and shows how experts make sense of the internal and external insights, and on the basis of this create new product concepts. Thereby the study proposes a shift in the present research agenda from what can be seen on the outside (actors and processes) to what happens on the inside.

Furthermore, the project contributes to the framing theory (Schön, 1983; Dorst, 2011) by introducing the concepts of reapplied and renewing frames.

The research also opens several avenues for future studies. It raises many interesting questions, such as: How are these internal and external are frames are selected? How to identify which internal frames to keep and which to toss? Which external frames to incorporate? Can a firm be characterized through a number of frames? How are the different internal and external frames aligned into a meaningful product? Can conflicting frames exists within the same product?

For practitioners, the model can raise awareness of what they do when conceptualizing. The model can systematically help convey the core of a product concept, helping to be explicit around the concept work, hence improve proficiency. In showing the informants the analysis and model to secure data correctness, an informant explicitly states: "The model can help me in being conscious of what I preach - and how I can articulate a new concept".

\section{References}

Acklin, C. (2009), “Design-Driven Innovation Process Model”, Design Korea 2009 International Conference, pp. 1-8.

Anderson, P. and Tushman, M.L. (1990), "Technological Discontinuities and Dominant Designs: A Cyclical Model of Technological Change", Administrative Science Quarterly, Vol. 35 No. 4, pp. 604-633. https://doi.org/10.2307/2393511 
Arora, A. and Gambardella, A. (1990), "Complementarity and External Linkages: The Strategies of the Large Firms in Biotechnology", The Journal of Industrial Economics, Vol. 38 No. 4, pp. 361-379. https://doi.org/10.2307/2098345

Bercovitz, J.E.L. and Feldman, M.P. (2007), "Fishing upstream: Firm innovation strategy and university research alliances", Research Policy, Vol. 36 No. 7, pp. 930-948. https://doi.org/10.1016/j.respol.2007.03.002

Buchanan, R. (1992), "Wicked Problems in Design Thinking”, Design Issues, Vol. 8 No. 2, pp. 5-21. https://doi.org/10.2307/1511637

Buijs, J. (2012), The Delft Innovation Method: A Design Thinker's Guide to Innovation, Eleven International Publishing.

Calabretta, G., Montaña, J. and Iglesias, O. (2015), “A cross-cultural assessment of leading values in designoriented companies”, Cross Cultural Management: An International Journal, Vol. 15 No. 4, pp. 379-398. https://doi.org/10.1108/13527600810914166

Cassiman, B. and Veugelers, R. (2006), "In search of complementarity in innovation strategy: Internal R\&D and external knowledge acquisition", Management Science, Vol. 52 No. 1, pp. 68-82. https://doi.org/10.1287/mnsc. 1050.0470

Chesbrough, H.W. (2003), Open Innovation: The New Imperative for Creating and Profiting from Technology, Harvard Business Press.

Cohen, W.M. and Levinthal, D.A. (1994), "Fortune Favors the Prepared Firm”, Management Science, Vol. 40 No. 2, pp. 227-251. https://doi.org/10.1287/mnsc.40.2.227

Dell'Era, C. and Verganti, R. (2009), "Design-driven laboratories: Organization and strategy of laboratories specialized in the development of radical design-driven innovations", $R \& D$ Management, Vol. 39 No. 1, pp. 1-20. https://doi.org/10.1111/j.1467-9310.2008.00541.x

Dell'Era, C. and Verganti, R. (2010), “Collaborative Strategies in Design-intensive Industries: Knowledge Diversity and Innovation”, Long Range Planning, Vol. 43 No. 1, pp. 123-141. https://doi.org/10.1016/j.lrp.2009.10.006

Dorst, K. (2011), “The core of "design thinking” and its application”, Design Studies, Vol. 32 No. 6, pp. 521-532. https://doi.org/10.1016/j.destud.2011.07.006

Dorst, K. (2015), Frame Innovation: Create New Thinking by Design, Massachusetts Institute of Technology.

Eisenhardt, K.M. and Graebner, M.E. (2007), "Theory building from cases: Opportunities and challenges", Academy of Management Journal, Vol. 50 No. 1, pp. 25-32. https://doi.org/ 10.5465/AMJ.2007.24160888

Filippetti, A. (2011), "Innovation modes and design as a source of innovation: a firm-level analysis", European Journal of Innovation Management, Vol. 14 No. 1, pp. 5-26. https://doi.org/10.1108/14601061111104670

Fleming, L. (2001), "Recombinant Uncertainty in Technological Search", Management Science, Vol. 47 No. 1 , pp. 117-132. https://doi.org/10.1287/mnsc.47.1.117.10671

Flyvbjerg, B. (2006), "Five Misunderstandings About Case-Study Research", Qualitative Inquiry, Vol. 12 No. 2 , pp. 219-245. https://doi.org/10.1177/1077800405284363

Grant, R.M. (1996), "Prospering in dynamically competitive environments: Organisational capability as knowledge integration", Organisation Science, Vol. 7 No. 4, pp. 375-387. https://doi.org/10.1287/orsc.7.4.375

Haase, L.M. and Laursen, L.N. (2018), "Reasoning in the Fuzzy Front End of Innovation: Framing the Product DNA", International Journal of Innovation Management.

Karim, S. and Mitchell, W. (2004), "Innovating through acquisition and internal development: A quarter-century of boudary evolution at Johnson \& Johnson”, Long Range Planning, Vol. 37 No. 6, pp. 525-547.

Nelson, R.R. and Winter, S.G. (1982), An Evolutionary Theory of Economic Change, Harvard University Press.

Phene, A., Fladmoe-Lindquist, K. and Marsh, L. (2006), "Breakthrough innovations in the U.S. biotechnology industry: The effects of technological space and geographic origin”, Strategic Management Journal, Vol. 27 No. 4, pp. 369-388. https://doi.org/10.1002/smj.522

Rittel, H.W.J. and Webber, M.M. (1973), "Dilemmas in a General Theory of Planning”, Policy Sciences, Vol. 4 No. 2, pp. 155-169.

Rosenkopf, L. and Almeida, P. (2003), “Overcoming Local Search Through Alliances and Mobility”, Management Science, Vol. 49 No. 6, pp. 751-766. https://doi.org/10.1287/mnsc.49.6.751.16026

Rosenkopf, L. and Nerkar, A. (2001), "Beyond local search: Boundary-spanning, exploration, and impact in the optical disk industry", Strategic Management Journal, Vol. 22 No. 4, pp. 287-306. https://doi.org/10.1002/smj.160

Sampson, R.C. (2007), "R\&D alliances and firm performance: The impact of technological diversity and alliance organization on innovation", Academy of Management Journal, Vol. 50 No. 2, pp. 364-386.

Schön, D.A. (1983), The reflective practitioner, Basic Books, New York.

Schön, D.A. (1995), Frame Reflection: Toward The Resolution Of Intractrable Policy Controversies, Basic Books, New York. 
Stake, R. (1995), The Art of Case Study Research, SAGE.

Ulrich, K.T. and Eppinger, S.D. (2008), Product Design and Development, McGraw-Hill.

Valkenburg, R. and Dorst, K. (1998), “The reflective practice of design teams”, Design Studies, Vol. 19 No. 3 , pp. 249-271. https://doi.org/10.1016/S0142-694X(98)00011-8

Weick, K.E. (2001), Making sense of the organization, Blackwell Publishing Ltd., Malden.

Weiss, R.S. (1995), Learning from Strangers: The Art and Method of Qualitative Interview Studies, Simon \& Schuster.

Yin, R.K. (2009), Case study research: design and methods, SAGE.

Dr. Linda Nhu Laursen, Post Doc

Aalborg University, Design and Media Technology

Rendsburgsgade 14, 9000 Aalborg, Denmark

Email: linda@create.aau.dk 